\title{
Methods for Designing Concurrently Strengthened Severely Deformed Age-Hardenable Aluminum Alloys by Ultrafine-Grained and Precipitation Hardenings
}

\author{
SHOICHI HIROSAWA, TAKUMI HAMAOKA, ZENJI HORITA, SEUNGWON LEE, \\ KENJI MATSUDA, and DAISUKE TERADA
}

The age-hardenings behavior and precipitate microstructures with high dislocation density and/ or ultrafine grains have been studied for $6022 \mathrm{Al}-\mathrm{Mg}-\mathrm{Si}$ and 2091 Al-Li-Cu alloys. The highpressure torsion (HPT) specimen of the former alloy exhibited either suppressed age hardenings or even age softening, unlike in the cases of the undeformed and cold-rolled specimens, at room temperature (RT) to $443 \mathrm{~K}\left(170{ }^{\circ} \mathrm{C}\right)$. On the other hand, the HPT specimen of the latter alloy successfully increased the hardness up to $>\mathrm{HV} 290$ at $373 \mathrm{~K}\left(100{ }^{\circ} \mathrm{C}\right)$, suggesting that concurrent strengthening by ultrafine-grained and precipitation hardenings can be activated if both alloy system and aging temperature are optimally selected. The corresponding transmission electron microscopy (TEM) microstructures attributed such a high level of hardness to the transgranular precipitation of the nanometer-scale particles within ultrafine grains. From the results of in situ small-angle X-ray scattering (SAXS) measurements, methods to maximize the effect of the combined processing of severe plastic deformation (SPD) and the age-hardenings technique are proposed based on the underlying phase transformation mechanisms.

DOI: $10.1007 / \mathrm{s} 11661-013-1730-\mathrm{y}$

(c) The Minerals, Metals \& Materials Society and ASM International 2013

\section{INTRODUCTION}

IN general, strengthening mechanisms of aluminum alloys include strain hardenings, hardenings by grain refinement, solid-solution hardenings, and/or precipitation hardenings because no allotropic or martensitic transformation is available. Severe plastic deformation (SPD) such as equal-channel angular pressing (ECAP), accumulative roll bonding (ARB), and high-pressure torsion (HPT) has been successfully utilized as a method for improving the strength of metallic materials based on the first two strengthening mechanisms. ${ }^{[1]}$ However, the combined processing of SPD and age-hardenings treatment does not necessarily result in a further increase in strength of heat-treatable aluminum alloys, unlike in the case of non-heat-treatable aluminum alloys where solid-solution hardenings is almost additive to strain hardenings or ultrafine-grained hardenings (i.e., hardenings by grain refinement to the submicrometer or nanometer level). ${ }^{[2]}$ This is because if the microstructure of age-hardenable aluminum alloys is controlled for strain hardenings and/or ultrafine-grained hardenings,

SHOICHI HIROSAWA, Associate Professor, is with Yokohama National University, Yokohama 240-8501, Japan. Contact e-mail: hirosawa@ynu.ac.jp TAKUMI HAMAOKA, formerly with Yokohama National University, is now Assistant Professor with Tohoku University, Sendai 980-8577, Japan. ZENJI HORITA, Professor and SEUNGWON LEE, Postdoctoral Researcher, are with Kyushu University, Fukuoka 819-0395, Japan. KENJI MATSUDA, Professor, is with University of Toyama, Toyama 930-8555, Japan. DAISUKE TERADA, Assistant Professor, is with Kyoto University, Kyoto 606-8501, Japan.

Manuscript submitted February 22, 2013.

Article published online April 17, 2013 the subsequent precipitation hardenings is often limited due to the competitive precipitation among dislocations, grain boundaries, and the matrix. Table I summarizes previously reported experimental results on concurrent strengthening by SPD and the age-hardenings technique for a number of age-hardenable aluminum alloys. ${ }^{\left[{ }^{3-20]}\right.}$ Although the specimens under no SPD condition (i.e., equivalent strain less than 4) possess relatively good agehardenability, most of the severely deformed and then artificially aged specimens exhibit either suppressed age hardenings or age softening as denoted by smaller $\Delta$ or large $\boldsymbol{\nabla}$. The following are the main features extracted from Table I, where attained values of hardness/ strength, the degree of age hardenings/softening, and the corresponding microstructures are reviewed according to the alloy system, equivalent strain, and aging temperature.

(i) The higher the aging temperature applied, the lower the attained hardness/strength and the degree of age hardenings. This is of course not unusual regardless of the application of SPD, but the degree appears to be significant (Indeed, in some cases, only age softening occurs). This can be explained not only by the more predominant recovery of dislocations and growth of ultrafine grains but also by coarsened precipitation of stable phases at dislocations and grain boundaries, resulting in suppressed transgranular precipitation of refined metastable particles (i.e., competitive precipitation).

(ii) The larger the equivalent strain introduced by SPD, the lower the degree of age hardenings at a fixed aging temperature. This is also due to the 


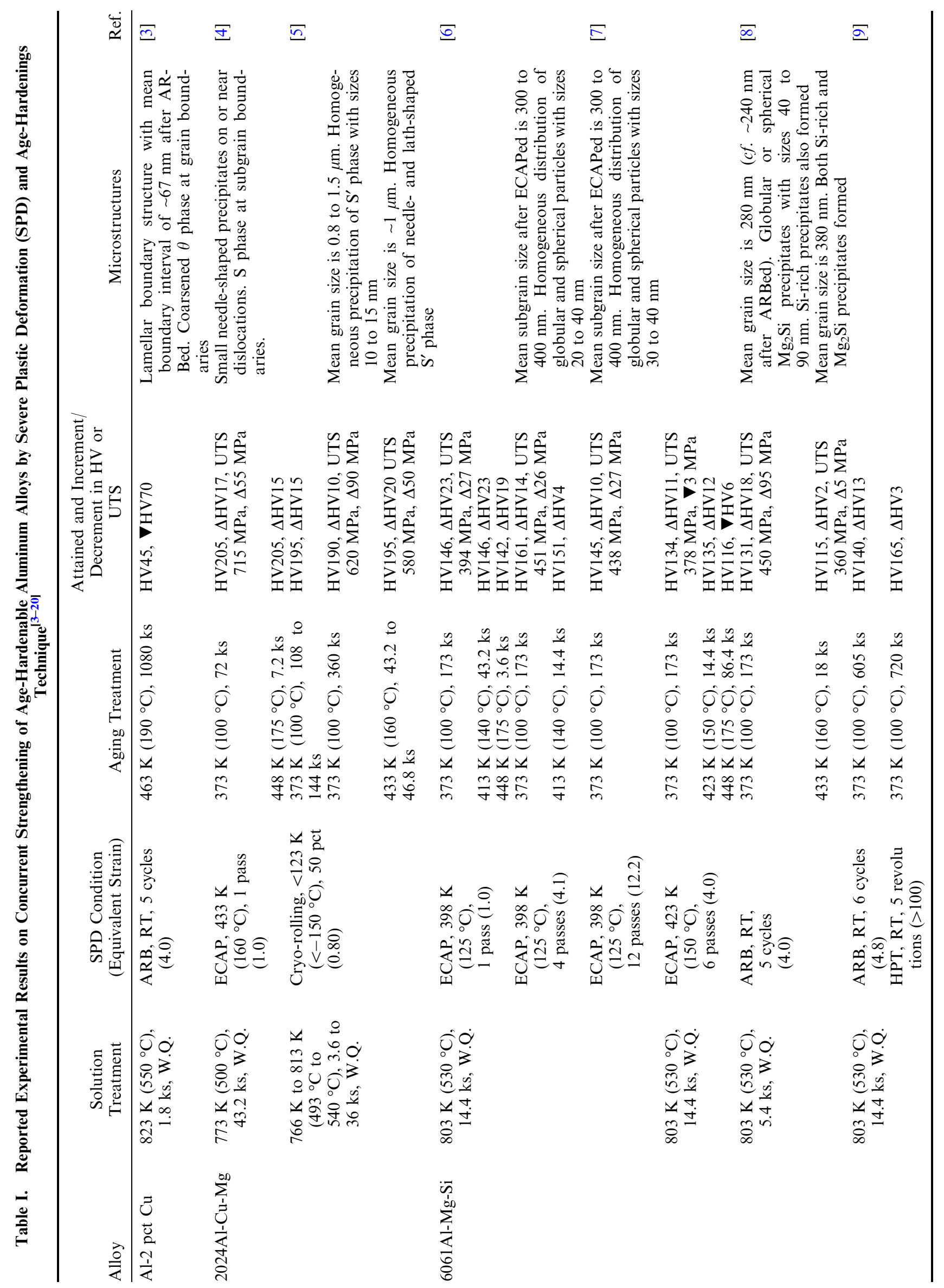




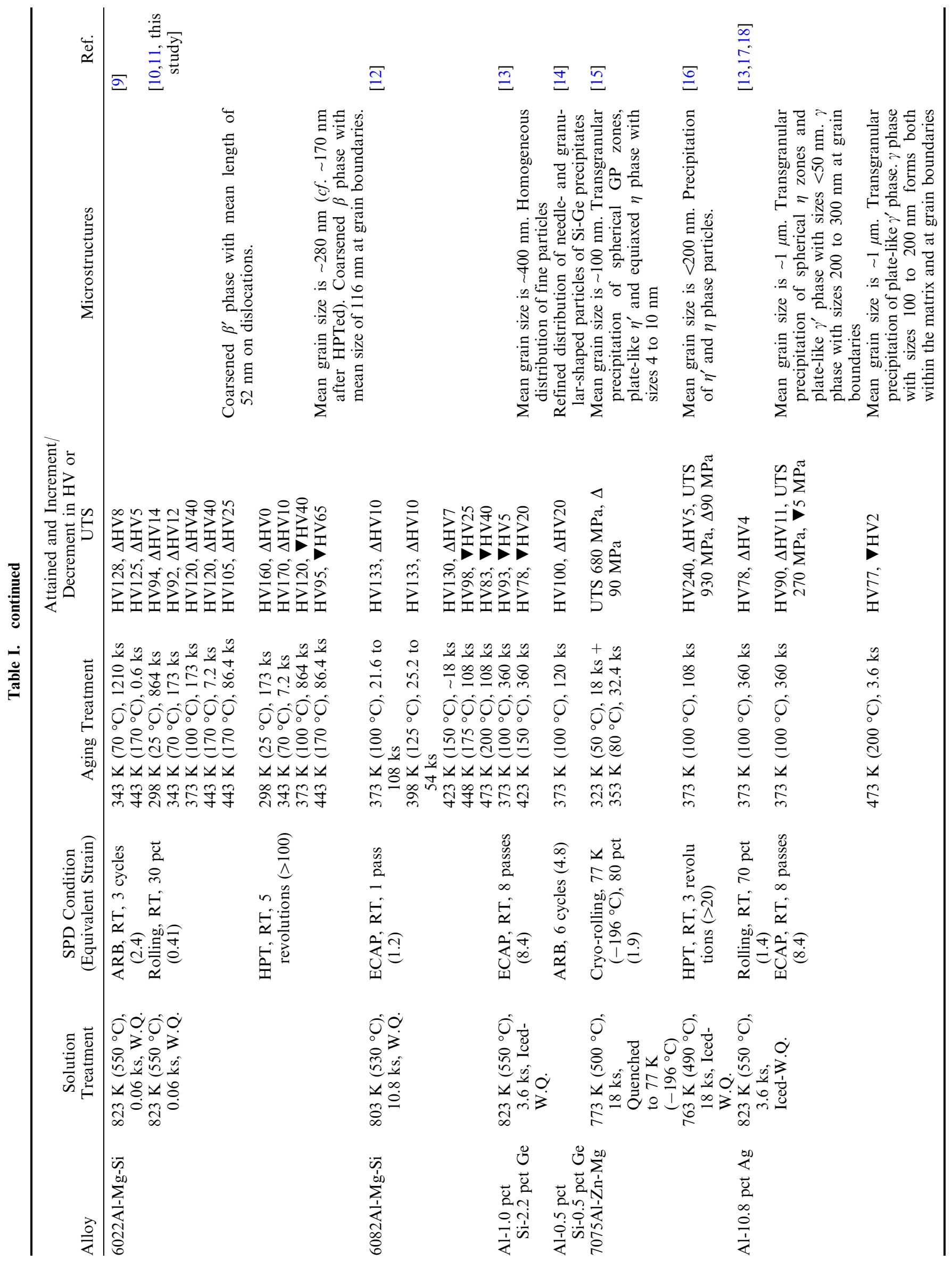




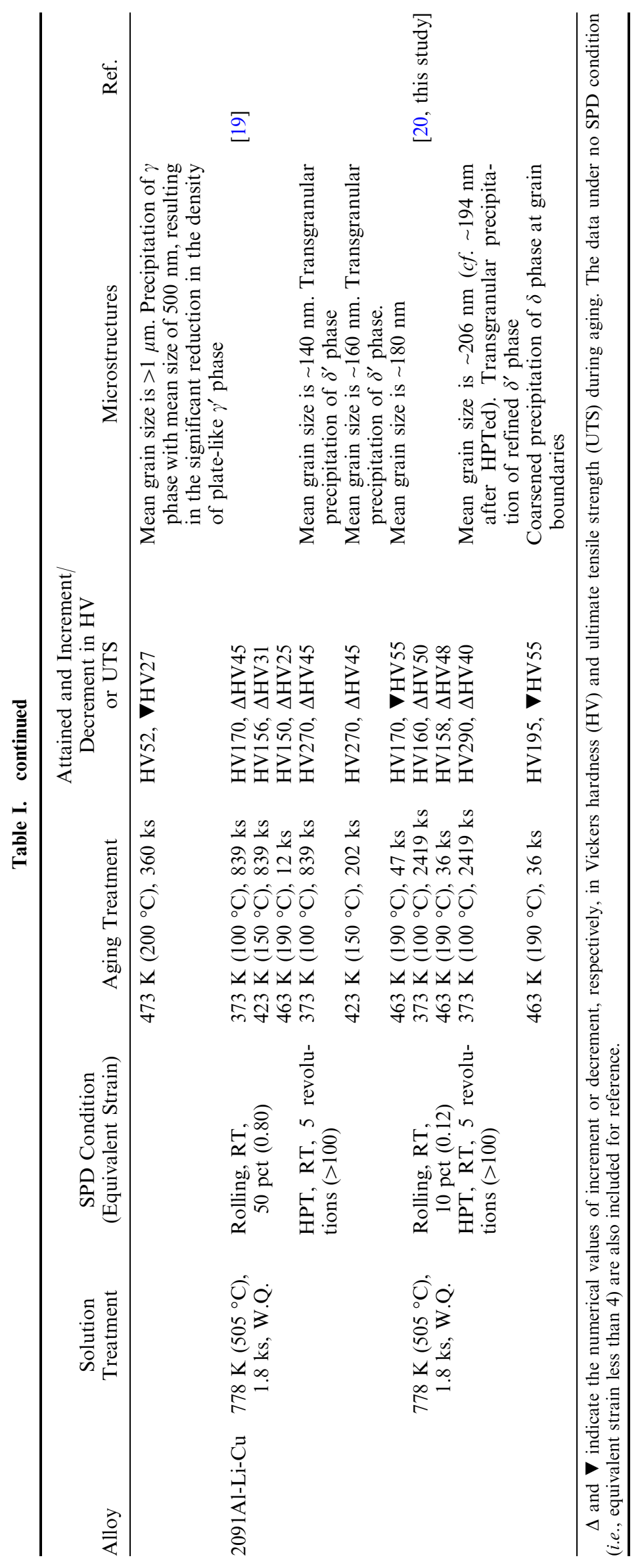


Table II. Chemical Compositions of the Alloys Utilized in this Study (Mass Pet)

\begin{tabular}{|c|c|c|c|c|c|c|c|c|}
\hline Alloy & $\mathrm{Mg}$ & $\mathrm{Si}$ & $\mathrm{Cu}$ & $\mathrm{Li}$ & $\mathrm{Zr}$ & $\mathrm{Fe}$ & $\mathrm{Ti}$ & $\mathrm{Al}$ \\
\hline 6022 & 0.57 & 1.02 & - & - & - & 0.17 & - & bal. \\
\hline 2091 & 1.55 & 0.03 & 1.99 & 2.09 & 0.12 & 0.05 & 0.03 & bal. \\
\hline
\end{tabular}

competitive precipitation in which dislocations and grain boundaries serve as heterogeneous nucleation sites for stable phases, restricting transgranular precipitation of strengthening phases. Unfortunately, we have to say at present that the best agehardenability can be obtained in the undeformed specimens with no equivalent strain.

(iii) When comparing alloy systems, all of commercial 2000 (Al-Cu-Mg), 6000 (Al-Mg-Si), and 7000 (Al$\mathrm{Zn}-\mathrm{Mg}$ ) series aluminum alloys, as well as model alloys of Al-Si-Ge and Al-Ag, exhibit suppressed age hardenings as high as $\triangle \mathrm{HV} 30$ under SPD conditions. This suggests again that concurrent strengthening by ultrafine-grained and precipitation hardenings is hardly activated. However, the authors reported recently that the HPT specimen of 2091Al-Li-Cu can increase the hardness up to HV270-290 by taking advantage of both initial hardenings by grain refinement (i.e., $225-250 \mathrm{HV}$ after HPTed) and subsequent age hardenings of $\Delta$ HV40 to $45 .^{[19,20]}$ This attained hardness is almost the highest among conventional wrought aluminum alloys and is certainly attributed to transgranular precipitation of nanometer-scale particles within ultrafine grains. Therefore, the combined processing of SPD and the age-hardenings technique still appears to leave open the possibility to fabricate novel aluminum alloys concurrently strengthened by ultrafine-grained and precipitation hardenings.

In this study, the age-hardenings behavior and precipitate microstructures of two age-hardenable aluminum alloys of 6022Al-Mg-Si and 2091Al-Li-Cu were investigated under the cold-rolled and severely deformed conditions. Although our preliminary studies ${ }^{[10,11,19,20]}$ classified the former into the alloy with limited effect of concurrent strengthening and the latter into the alloy with noteworthy effect, no comprehensive and comparative studies had been conducted, especially concerning the reason why such a difference in age-hardenability arises depending on alloy system and aging temperature. Our proposed method for designing concurrently strengthened severely deformed age-hardenable aluminum alloys ${ }^{[20]}$ will be also verified based on the underlying phase transformation mechanisms, i.e., the nucleation and growth or spinodal decomposition (following after congruent ordering), detected by in situ small-angle X-ray scattering (SAXS) measurement.

\section{EXPERIMENTAL PROCEDURE}

Commercial 6022 and 2091 alloy cold-rolled sheets with a thickness of $1.0 \mathrm{~mm}$ (for 6022) or $1.6 \mathrm{~mm}$ (for
2091) were utilized in this study. The chemical compositions of the two alloys are listed in Table II. 10-mm squares and $10-\mathrm{mm} \phi$ disks were cut from the sheets and solution-treated in a salt bath at $823 \mathrm{~K}\left(550^{\circ} \mathrm{C}\right)$ for 60 seconds (for 6022$)$ or at $778 \mathrm{~K}\left(505^{\circ} \mathrm{C}\right)$ for $1.8 \mathrm{ks}$ (for 2091), followed by water quenching. Cold rolling and HPT were performed at room temperature [RT, $\sim 298 \mathrm{~K}\left(25^{\circ} \mathrm{C}\right)$ ] within $3.6 \mathrm{ks}$ after quenching, with rolling reduction of 30 pct (for 6022) or 10 pct (for 2091), and under a pressure of $6 \mathrm{GPa}$ for 5 revolutions with a rotation speed of $1 \mathrm{rpm}$ (for 6022 and 2091; the details of the HPT facility and operating procedures were reported $\mathrm{in}^{[21]}$ ). The corresponding equivalent strain is $0.41,0.12$, and $>100$ (in the regions more than $1 \mathrm{~mm}$ away from the center of the HPTed disks ${ }^{[19]}$ ).

Square pieces of the undeformed and cold-rolled specimens as well as disks of the HPT specimen were subsequently subjected to aging treatment in oil baths at $343 \mathrm{~K}$ to $463 \mathrm{~K}\left(70{ }^{\circ} \mathrm{C}\right.$ to $\left.190{ }^{\circ} \mathrm{C}\right)$ for various times. The surface of each heat-treated specimen was mechanically polished to eliminate $\mathrm{Mg}$ and/or Li loss layers induced by solution treatment. The age-hardenings behavior of the three specimens was investigated by a microhardness tester (Matsuzawa MMT-X1) with a load of $500 \mathrm{~g}$ for a dwelling time of 15 seconds. The hardness of each specimen was determined as an average value of five tested points out of seven ones with an accuracy of \pm HV2. For the HPTed disks, the indenter was carefully pressed into the regions more than $3 \mathrm{~mm}$ away from the center to avoid unsaturated levels of hardness being measured. ${ }^{[19]}$

The foils for transmission electron microscopy (TEM) observation were punched out in a form of $3-\mathrm{mm} \phi$ disks and thinned by the electrolytic twin-jet polishing technique in $20 \mathrm{vol}$ pet nitric acid with 80 vol pet methanol at $\sim 253 \mathrm{~K}\left(-20^{\circ} \mathrm{C}\right)$. TEM microstructures and the corresponding selected-area electron diffraction (SAED) patterns were observed using a JEM-2100F microscope at an accelerating voltage of $200 \mathrm{kV}$. Special attention was paid again to the preparation of TEM foils for the HPT specimen; i.e., 3-mm $\phi$ disks were punched out from regions far away from the center of the original 10mm $\phi$ disk. [19]

The wafers for small-angle X-ray scattering (SAXS) measurement were prepared as thin square pieces of $\sim 200 \mu \mathrm{m}$ thickness for the undeformed specimen of 2091 Al-Li- $\mathrm{Cu}$ under the as-quenched condition. The thickness was preliminarily determined to achieve ideal transmission coefficient, e.g., $\sim 0.1$, for $\mathrm{CuK} \alpha$ radiation generated from an $18-\mathrm{kW}$ rotating anode X-ray source. SAXS measurement was performed using a Bruker NanoSTAR SAXS system with a sample-to-detector distance of $1.06 \mathrm{~m}$, by which a measurable range of scattering vectors $q=4 \pi \sin \theta / \lambda$ is defined as 0.06 to 
$7.5 \mathrm{~nm}^{-1}$. Here, $2 \theta$ is the scattering angle and $\lambda$ is the wavelength of $\mathrm{CuK} \alpha(0.154 \mathrm{~nm})$. The scattering intensity $I$ from an area of $\sim 1 \mathrm{~mm} \phi$ within the wafer specimen (i.e., point focus geometry) was recorded on a twodimensional PSPC detector in an in situ manner at $373 \mathrm{~K}$ and $463 \mathrm{~K}\left(100{ }^{\circ} \mathrm{C}\right.$ and $\left.190{ }^{\circ} \mathrm{C}\right)$. The temperature of the wafer mounted on a miniature hot stage was controlled to an accuracy of $\pm 0.7 \mathrm{~K}\left( \pm 0.7^{\circ} \mathrm{C}\right)$, and the counting time per measurement lasted for 300 to 600 seconds to obtain acceptable counting statics. Measurements at prolonged aging times, i.e., 432 and $2419 \mathrm{ks}$ at $373 \mathrm{~K}$ $\left(100^{\circ} \mathrm{C}\right)$, were conducted in an ex situ manner using the same wafer as that for in situ measurements at earlier aging times. Correction was applied for background noise, but no calibration was done for the normalization of $I$ to absolute scattering intensities.

\section{EXPERIMENTAL RESULTS}

\section{A. Concurrent Strengthening of 6022Al-Mg-Si Alloy}

Figure 1 shows the Vickers hardness change of the undeformed, cold-rolled, and HPT specimens of 6022Al-Mg-Si during aging at RT-443 K $\left(170{ }^{\circ} \mathrm{C}\right)$. It is confirmed from the initial hardness that the two deformation processes, i.e., cold rolling by $30 \mathrm{pct}$ and HPT for 5 revolutions, increased the hardness of the undeformed specimen from $\sim \mathrm{HV} 45$ to $\sim \mathrm{HV} 80$ or $\sim$ HV160, depending on the equivalent strain introduced. This strengthening can be explained by the correspond- ing TEM microstructures, i.e., strain hardenings by a high dislocation density in the cold-rolled specimen (Figure 2(b)) and ultrafine-grained hardenings by submicrometer-scale grains in the HPT specimen (Figure 2(c)). Note that many of these grains were separated by high-angle grain boundaries ${ }^{[19]}$ and, therefore, retained a relatively low dislocation density as a result of absorption of dislocations at the high-angle grain boundaries. ${ }^{[22]}$

In the subsequent stage of aging, however, the two deformation processes either suppressed the age-hardenability of this alloy system or even induced age softening. For example, the hardness of the cold-rolled and HPT specimens changed by $>\Delta \mathrm{HV} 12$ and $\Delta \mathrm{HV} 10$ at $343 \mathrm{~K}\left(70{ }^{\circ} \mathrm{C}\right)$, or by $\Delta \mathrm{HV} 40$ and $\mathbf{V H V} 65$ at $443 \mathrm{~K}$ $\left(170{ }^{\circ} \mathrm{C}\right)$ (see Figures $1(\mathrm{~b})$ and (d) or Table I), supporting the above-mentioned features (i) and (ii); i.e., the higher the aging temperature applied or the larger the equivalent strain introduced, the lower the degree of age hardenings. These changes are much lower than those of the undeformed specimen, i.e., $>\Delta \mathrm{HV} 40$ at $343 \mathrm{~K}$ $\left(70{ }^{\circ} \mathrm{C}\right)$ and $\Delta \mathrm{HV} 75$ at $443 \mathrm{~K}\left(170^{\circ} \mathrm{C}\right)$, and are therefore suggesting that the combined processing of SPD and age-hardenings treatment unfavorably decreases the potential age-hardenability of $6022 \mathrm{Al}-\mathrm{Mg}-\mathrm{Si}$. Figure 2(d) through (f) shows typical TEM microstructures of the three specimens aged at $443 \mathrm{~K}\left(170^{\circ} \mathrm{C}\right)$ for $86.4 \mathrm{ks}$. The transgranular precipitation of the refined $\beta^{\prime \prime}$ phase with a mean length of $\sim 35 \mathrm{~nm}$ was predominant in the undeformed specimen (Figure 2(d)), whereas larger precipitates of the $\beta^{\prime \prime}$ needles were
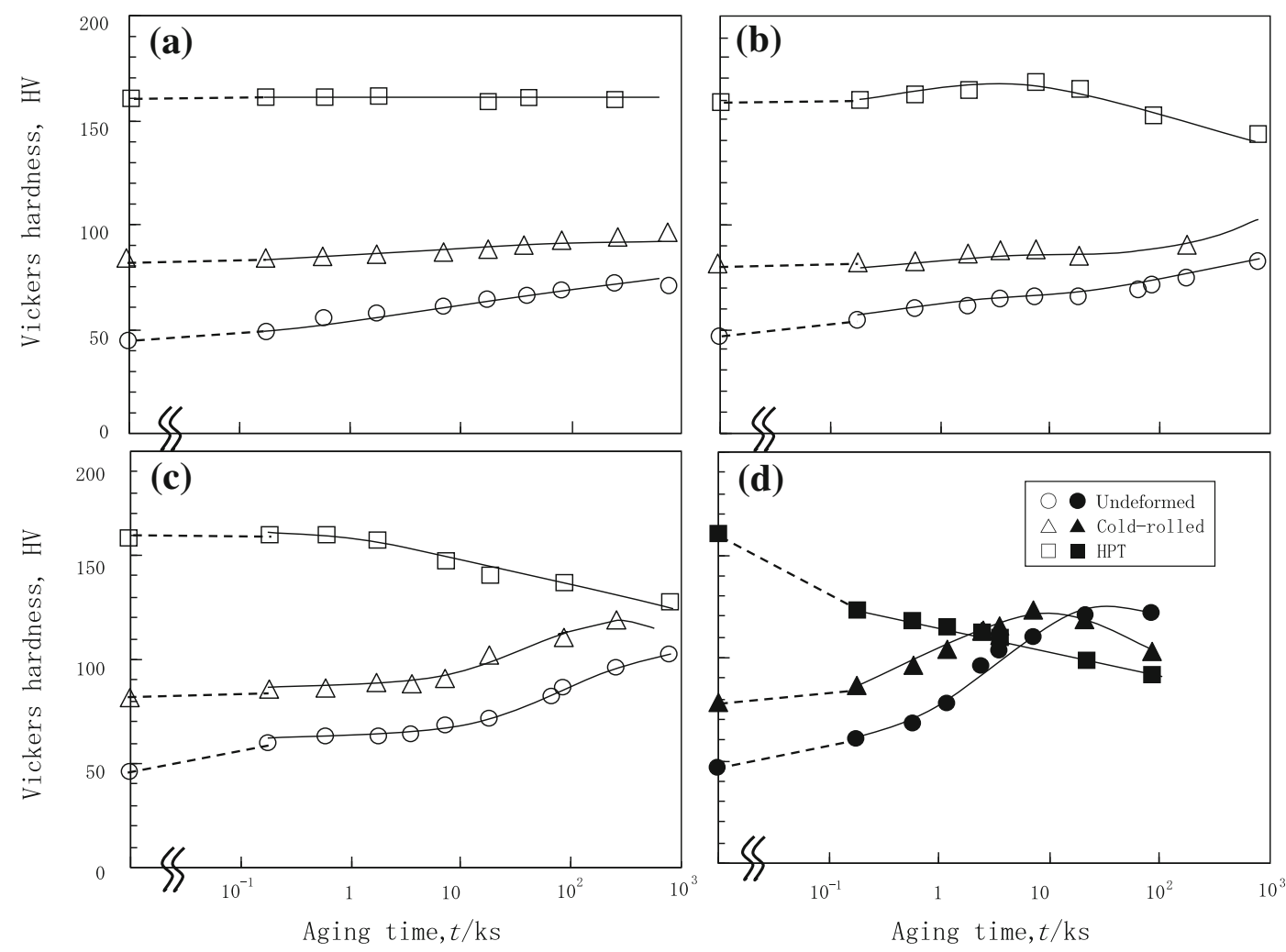

Fig. 1-Vickers hardness change of the undeformed, cold-rolled, and HPT specimens of $6022 \mathrm{Al}-\mathrm{Mg}$-Si during aging at RT (a) $298 \mathrm{~K}\left(25^{\circ} \mathrm{C}\right)$, (b) $343 \mathrm{~K}\left(70{ }^{\circ} \mathrm{C}\right),(c) 373 \mathrm{~K}\left(100^{\circ} \mathrm{C}\right)$, and $(d) 443 \mathrm{~K}\left(170^{\circ} \mathrm{C}\right)$. 

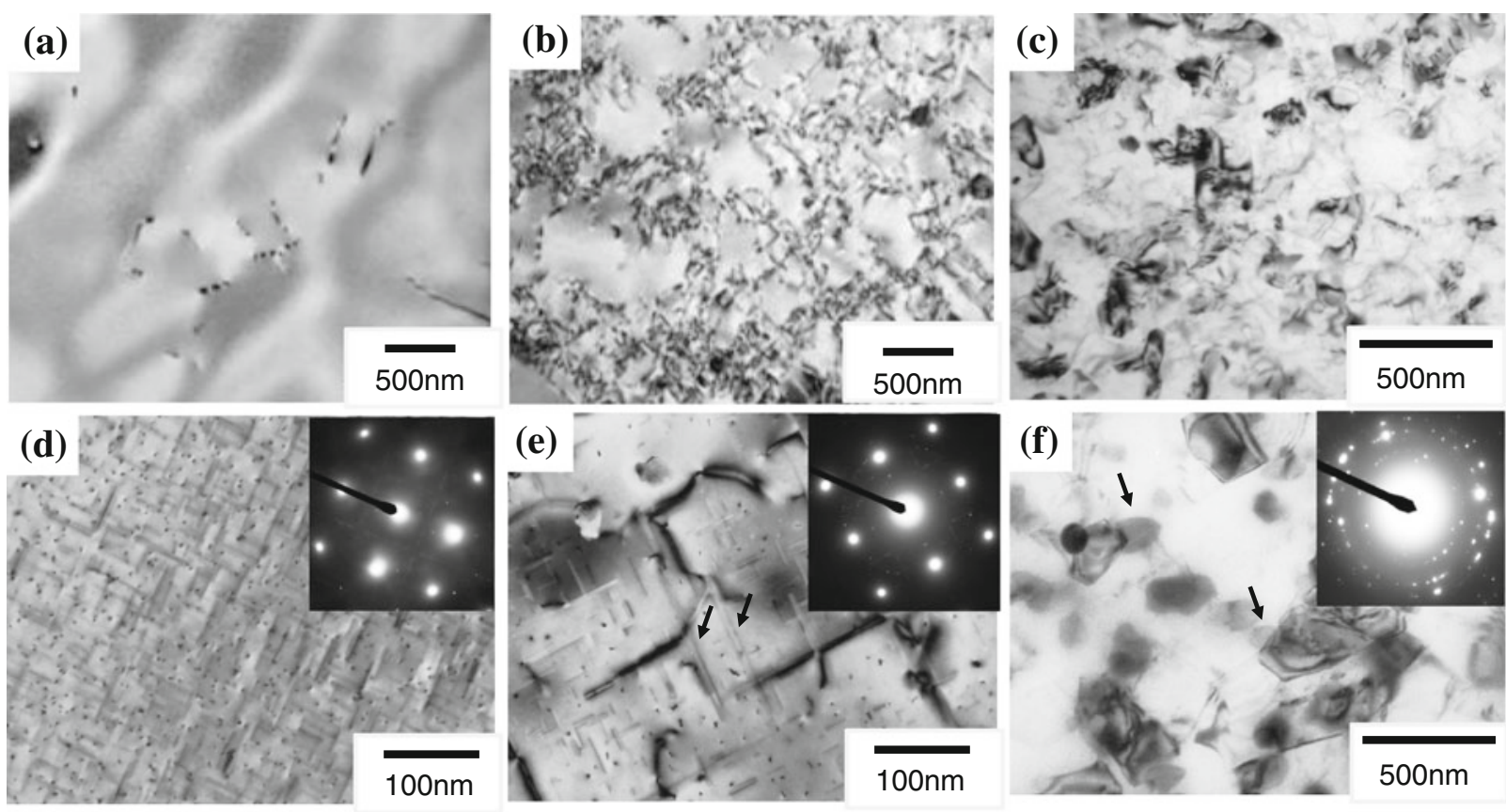

Fig. 2-Bright-field TEM images and the corresponding SAED patterns of the undeformed $(a, d)$, cold-rolled $(b, e)$, and HPT $(c, f)$ specimens of $6022 \mathrm{Al}-\mathrm{Mg}$-Si before aging (a through c) and after aging at $443 \mathrm{~K}\left(170{ }^{\circ} \mathrm{C}\right)$ for $86.4 \mathrm{ks}(\mathrm{d}$ through f).

heterogeneously formed on dislocations in the coldrolled specimen (as arrowed in Figure 2(e)). In the HPT specimen, on the other hand, the coarsened $\beta-\mathrm{Mg}_{2} \mathrm{Si}$ phase with sizes of a few hundred nanometers was precipitated at grain boundaries (as arrowed in Figure 2(f)), resulting in the complete suppression of transgranular precipitation of refined $\beta^{\prime \prime}$. Such competitive precipitation among dislocations, grain boundaries, and the matrix is obviously attributed to the reduced agehardenability or significant age softening of the coldrolled and HPT specimens in Figure 1. Recovery of dislocations and growth of ultrafine grains will be also the origin of such unfavorable decrease in age-hardenability with more pronounced tendencies at higher aging temperatures or at larger equivalent strain.

\section{B. Concurrent Strengthening of 2091 Al-Li-Cu Alloy}

Figure 3 shows the Vickers hardness change of the undeformed, cold-rolled, and HPT specimens of 2091 Al-Li-Cu during aging at $373 \mathrm{~K}$ and $463 \mathrm{~K}$ $\left(100{ }^{\circ} \mathrm{C}\right.$ and $\left.190{ }^{\circ} \mathrm{C}\right)$. The initial hardness before aging at $\sim \mathrm{HV} 85, \sim \mathrm{HV} 110$, and $\sim \mathrm{HV} 250$ suggests again that strain hardenings and ultrafine-grained hardenings are activated by means of cold rolling by 10 pct and HPT for 5 revolutions. This can be verified by the corresponding TEM microstructures in Figure 4(b) and (c), which demonstrates either a higher dislocation density or finer grains with high-angle grain boundaries for the cold-rolled and HPT specimens than those in the undeformed specimen (Figure 4(a)).

In contrast, unlike in the case of $6022 \mathrm{Al}-\mathrm{Mg}-\mathrm{Si}$, concurrent strengthening by SPD and the age-hardenings technique was successfully activated in the investigated 2091Al-Li-Cu alloy. For example, the hardness of
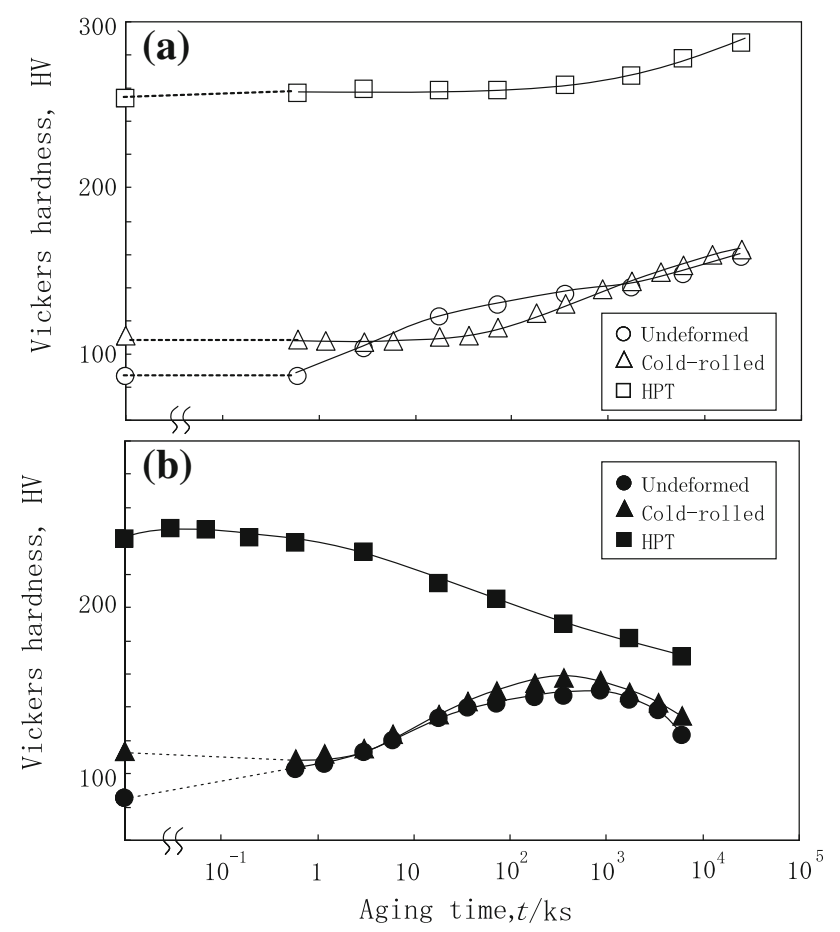

Fig. 3-Vickers hardness change of the undeformed, cold-rolled, and HPT specimens of $2091 \mathrm{Al}-\mathrm{Li}-\mathrm{Cu}$ during aging at (a) $373 \mathrm{~K}\left(100{ }^{\circ} \mathrm{C}\right)$ and $(b) 463 \mathrm{~K}\left(190{ }^{\circ} \mathrm{C}\right)$.

the HPT specimen changed by $>\Delta \mathrm{HV} 40$ at $373 \mathrm{~K}$ $\left(100{ }^{\circ} \mathrm{C}\right)$ and reached almost the highest level of $>$ HV290 among conventional wrought aluminum alloys (see Figure 3(a) or Table I). This suggests that the combination of HPT and age-hardenings treatment 

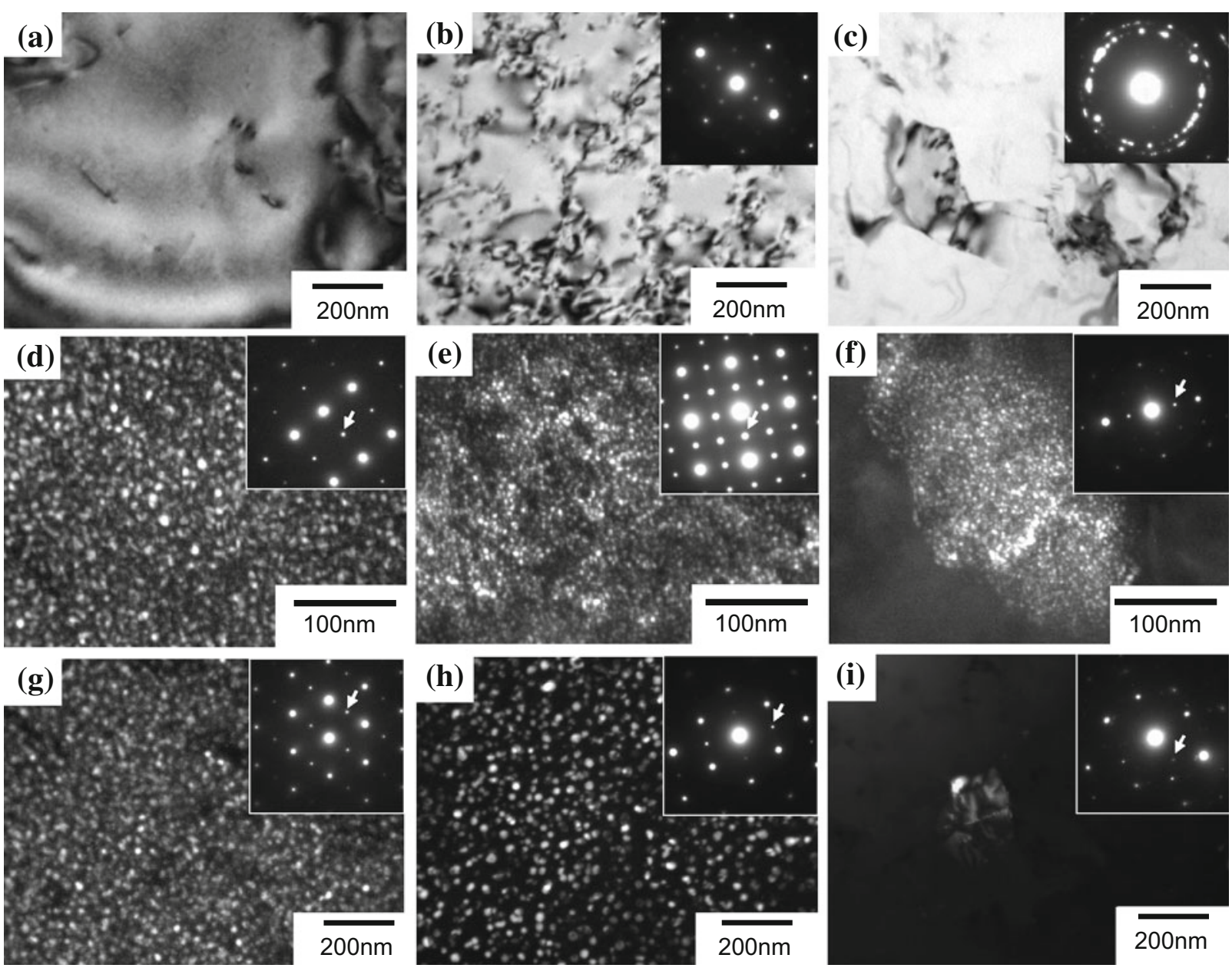

Fig. 4-Bright-field ( $a$ through $c$ ) and dark-field ( $d$ through $i$ ) TEM images and the corresponding SAED patterns of the undeformed (a, d, g), cold-rolled (b, e, h), and HPT (c, f, i) specimens of 2091Al-Li-Cu before aging ( $a$ through $c$ ), after aging at $373 \mathrm{~K}\left(100{ }^{\circ} \mathrm{C}\right)$ for $2419 \mathrm{ks}$ $(d$ through $f)$, and after aging at $463 \mathrm{~K}\left(190^{\circ} \mathrm{C}\right)$ for $36 \mathrm{ks}(g$ through $i)$.

enables 2091 Al- $\mathrm{Li}-\mathrm{Cu}$ to be strengthened without diminishing extensively the excellent age-hardenability of the undeformed specimen, i.e., $>\Delta$ HV75. Figure $4(\mathrm{~d})$ through (f) shows TEM microstructures of the three specimens aged at $373 \mathrm{~K}\left(100{ }^{\circ} \mathrm{C}\right)$ for $2419 \mathrm{ks}$. The dark-field image of the HPT specimen reveals that quite refined $\delta^{\prime}-\mathrm{Al}_{3} \mathrm{Li}$ particles precipitate within the ultrafine grains of $\sim 206 \mathrm{~nm}$ size (Figure 4(f)), as with the cases of the undeformed and cold-rolled specimens (Figure 4(d) and (e)). Note that no notable amount of coarsened precipitates was formed at grain boundaries, and the growth of ultrafine grains during aging was less pronounced, i.e., $\sim 194$ to $\sim 206 \mathrm{~nm}$, at this temperature.

If the applied aging temperature is raised, however, the reduced age-hardenability and significant age softening were observed even in this alloy system. Figure 3(b) shows the age-hardenings/softening curves of the same three specimens, i.e., undeformed, cold-rolled, and HPT specimens of 2091 Al- $\mathrm{Li}-\mathrm{Cu}$, during aging at $463 \mathrm{~K}\left(190^{\circ} \mathrm{C}\right)$. Although a slightly higher peak hardness of the cold-rolled specimen indicates that T8 treatment (cold work + artificial aging) exerts a positive effect on the mechanical strength of the undeformed specimen, the HPT specimen with much larger equivalent strain only exhibited monotonous decrease in hardness, failing to take advantage of the initial hardness of $\sim 250 \mathrm{HV}$. Figure $4(\mathrm{~g})$ through (i) shows TEM microstructures of the three specimens aged at $463 \mathrm{~K}$ $\left(190{ }^{\circ} \mathrm{C}\right)$ for $36 \mathrm{ks}$. While spherical particles of the metastable $\delta^{\prime}$ phase homogeneously precipitate within the matrix of the undeformed and cold-rolled specimens (Figure 4(g) and (h)), only the coarsened $\delta$-AlLi phase was found to form sparsely at grain boundaries in the HPT specimen (Figure 4(i)). This suggests that the fabrication of novel aluminum alloys concurrently strengthened by ultrafine-grained and precipitation hardenings depends not only on the selection of the alloy system but also on the optimization of aging temperature. Note that in this study, the main strengthening phase of this alloy system was regarded as $\delta^{\prime}-\mathrm{Al}_{3} \mathrm{Li}$, rather than $\mathrm{Cu}$ and $\mathrm{Mg}$ containing GPB zones or $\mathrm{S}^{\prime}-\mathrm{Al}_{2} \mathrm{CuMg}$ phase, because no clear evidence of such precipitation was obtained for the cold-rolled and HPT specimens, unlike in the case of the undeformed specimen where lath-shaped precipitates of the $S^{\prime}$ phase are sparsely formed. 


\section{Phase Transformation Mechanisms of 2091 Al- $\mathrm{Li}-\mathrm{Cu}$ Alloy}

Figure 5 illustrates the metastable two-phase field involving disordered $\alpha-\mathrm{Al}$ and ordered $\delta^{\prime}-\mathrm{Al}_{3} \mathrm{Li}$ in $\mathrm{Al}-\mathrm{Li}$ proposed by Khachaturyan et al. ${ }^{[23]}$ The two-phase field computed based on a mean field model is subdivided into four distinct regions, each of which is expected to follow a characteristic phase transformation path after rapid quenching of a supersaturated solid solution. If it is assumed that the boundaries do not shift so much even for the present multicomponent 2091 Al- $\mathrm{Li}-\mathrm{Cu}$, the aging temperatures applied in this study are located in region $\mathrm{B}$ for $373 \mathrm{~K}\left(100^{\circ} \mathrm{C}\right)$ and in region $\mathrm{D}$ for $463 \mathrm{~K}$ $\left(190{ }^{\circ} \mathrm{C}\right)$ because $\mathrm{Li}$ concentration of the alloy is $\sim 7.9$ at. pct. Therefore, since phase transformations occurring in the two regions are recognized as either spinodal decomposition following after congruent ordering or nucleation and growth of the $\delta^{\prime}$ phase, a convincing explanation of the different precipitate microstructures, and thus different age-hardenabilities, between $373 \mathrm{~K}$ and $463 \mathrm{~K}\left(100{ }^{\circ} \mathrm{C}\right.$ and $\left.190{ }^{\circ} \mathrm{C}\right)$ (Figures 3 and 4) appears to be drawn from their theoretic prediction on the underlying phase transformation mechanisms. ${ }^{[23]}$ In this study, experimental detection of such difference in phase transformation mechanisms was also conducted by in situ SAXS measurement.

Figure 6 shows in situ (ex situ) SAXS spectra for the undeformed specimen of 2091Al-Li-Cu aged at $373 \mathrm{~K}$ and $463 \mathrm{~K}\left(100{ }^{\circ} \mathrm{C}\right.$ and $\left.190{ }^{\circ} \mathrm{C}\right)$. The spectra were obtained by radially averaging isotropic scattering intensities on the recorded SAXS images and then expressing it as a function of $q$, i.e., $I(q) v s q$ plot. For the as-quenched condition, a strong scattering was observed below $q=0.2 \mathrm{~nm}^{-1}$, followed by a nearly flat background above it (see spectrum at $0 \mathrm{ks}$ in Figure 6(a); the similar spectrum was obtained at $0 \mathrm{ks}$ in $463 \mathrm{~K} \quad\left(190{ }^{\circ} \mathrm{C}\right)$ aging, but no data below $q=0.2 \mathrm{~nm}^{-1}$ are illustrated in Figure 6(b) for better

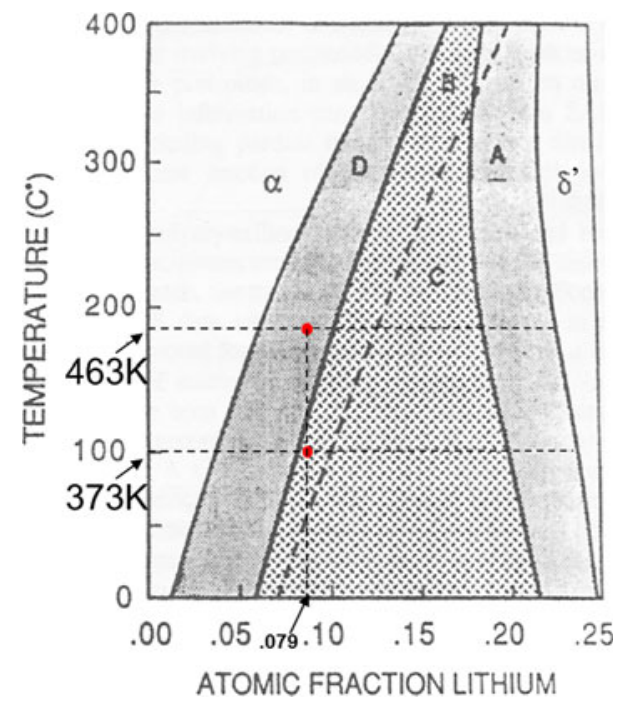

Fig. 5-Calculated metastable two-phase field of $\alpha-\mathrm{Al}+\delta^{\prime}-\mathrm{Al}_{3} \mathrm{Li}$ in Al-Li. ${ }^{[23]} \mathrm{Li}$ concentration of the utilized 2091Al- $\mathrm{Li}-\mathrm{Cu}$ and aging temperatures applied to the alloy are additionally plotted. visibility). This strong low- $q$ scattering is generally believed due to the existence of lattice defects (e.g., dislocations and grain boundaries), coarsened unsolved inclusions, and/or free specimen surfaces. With increasing aging time, however, the scattering intensity $I$ monotonously increased with/without an interparticle interference peak at intermediate $q$. At $373 \mathrm{~K}\left(100{ }^{\circ} \mathrm{C}\right)$, the interference peak grew in amplitude at a constant $q_{\mathrm{m}}$ and then shifted to a lower $q$ value (Figure 6(a); here, $q_{\mathrm{m}}$ was defined as the scattering vector showing the maximum intensity), whereas no interference peak was resolved during the evolution of $I$ at $463 \mathrm{~K}\left(190{ }^{\circ} \mathrm{C}\right)$ (Figure 6(b)). In this study, interparticle distance $L$ and Guinier radius $r_{\mathrm{G}}$ of precipitate particles were estimated as structural mean invariance through $L=2 \pi / q_{\mathrm{m}}$ for $373 \mathrm{~K}\left(100{ }^{\circ} \mathrm{C}\right)$ and through $\ln I(q) \sim \ln I(0)-r_{\mathrm{g}}^{2} q^{2} / 3$ (i.e., Guinier approximation) for $463 \mathrm{~K}\left(190^{\circ} \mathrm{C}\right)$, because such evolution of $I$ reflects the temporal change in volume fraction $V_{\mathrm{f}}$ of nanometer-scale inhomogeneities such as precipitate particles, ordered domains, and modulated structure. Here, the radius of gyration $r_{\mathrm{g}}$ was deduced from the profile of $\ln I(q)$ in the very low- $q$ region (e.g., $q<2 / r_{\mathrm{G}}$ ) of the Guinier plot, i.e., $I(q) v s q^{2}$ plot, and converted to $r_{\mathrm{G}}$ through $r_{\mathrm{G}}=\sqrt{(5 / 3) r_{\mathrm{g}}}$ because those microstructural inhomogeneities are basically of a spherical shape in this alloy system. Figure 7 summarizes the variation of $r_{\mathrm{G}}, L, V_{\mathrm{f}}$, and $N$ (number density) of precipitate particles in 2091 Al-Li-Cu during aging at $373 \mathrm{~K}$ and $463 \mathrm{~K}\left(100{ }^{\circ} \mathrm{C}\right.$ and $\left.190{ }^{\circ} \mathrm{C}\right)$. $V_{\mathrm{f}}$ was evaluated from integrated intensities $Q=\int 4 \pi q^{2} I(q) \mathrm{d} q$ underneath the profile of $q^{2} I(q)$ in Kratky plot, i.e.,
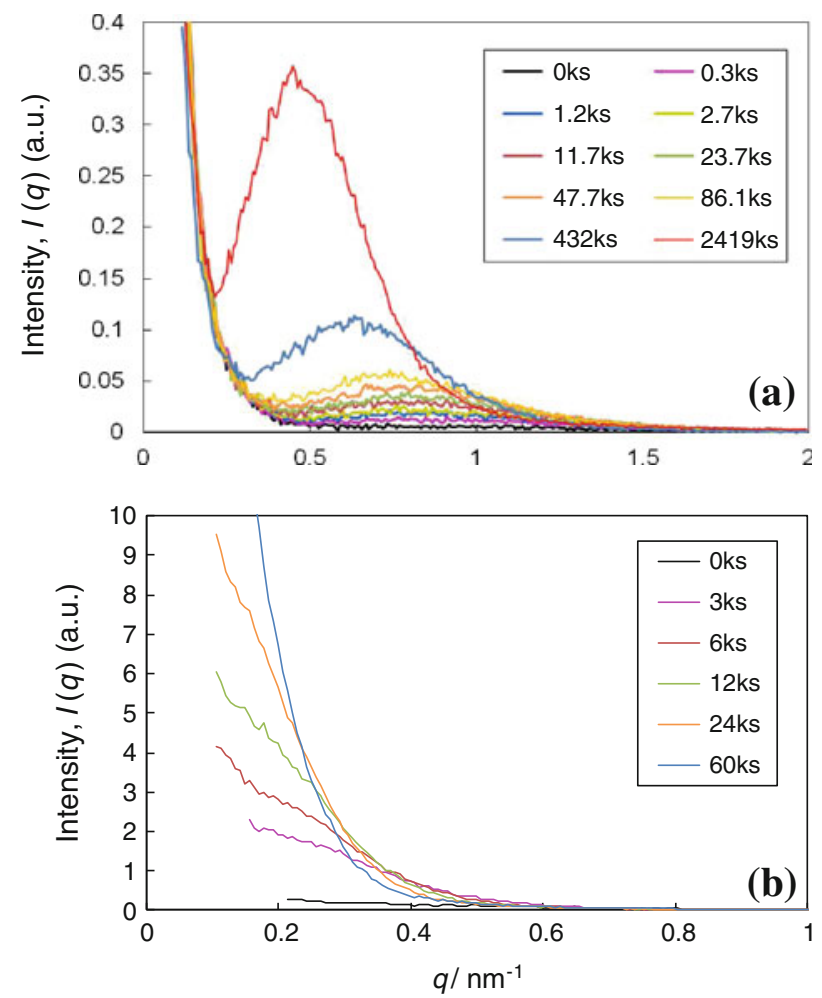

Fig. 6-In situ SAXS spectra for the undeformed specimen of 2091Al$\mathrm{Li}-\mathrm{Cu}$ aged at $(a) 373 \mathrm{~K}\left(100{ }^{\circ} \mathrm{C}\right)$ and $(b) 463 \mathrm{~K}\left(190^{\circ} \mathrm{C}\right)$. Only spectra at $373 \mathrm{~K}\left(100{ }^{\circ} \mathrm{C}\right)$ for 432 and $2419 \mathrm{ks}$ were obtained in an ex situ manner. 

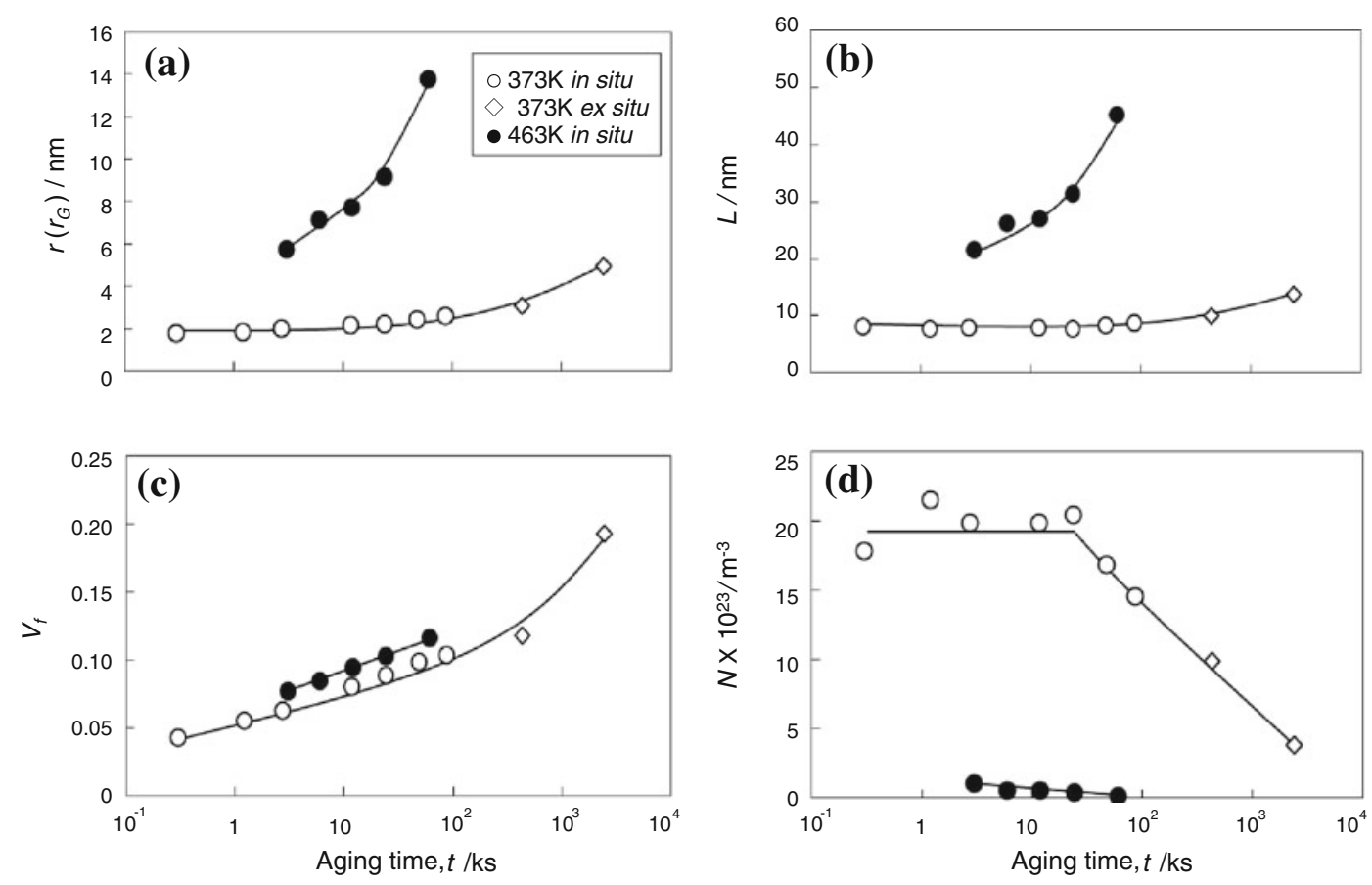

Fig. 7-Variation of (Guinier) radius $r_{\mathrm{G}}(a)$, interparticle distance $L(b)$, volume fraction $V_{\mathrm{f}}(c)$, and number density $N(d)$ of precipitate particles in the undeformed specimen of $2091 \mathrm{Al}-\mathrm{Li}-\mathrm{Cu}$ during aging at $373 \mathrm{~K}\left(100{ }^{\circ} \mathrm{C}\right)$ and $463 \mathrm{~K}\left(190{ }^{\circ} \mathrm{C}\right)$.

$q^{2} I(q)$ vs $q$ plot, under the assumption that $V_{\mathrm{f}}$ of the resultant $\delta^{\prime}$ phase obeys the lever rule in the two-phase field in Figure 5, i.e., $V_{\mathrm{f}}=0.22$ at $373 \mathrm{~K}\left(100^{\circ} \mathrm{C}\right)$ and $V_{\mathrm{f}}=0.132$ at $463 \mathrm{~K}\left(190{ }^{\circ} \mathrm{C}\right)$. Although the values of $r$ (radius) at $373 \mathrm{~K}\left(100{ }^{\circ} \mathrm{C}\right), L$ at $463 \mathrm{~K}\left(190{ }^{\circ} \mathrm{C}\right)$, and $N$ at both temperatures were calculated through geometric relationships, e.g., $r=L\left(3 V_{\mathrm{f}} / 4 \pi\right)^{1 / 3}, L=r_{\mathrm{G}}\left(4 \pi / 3 V_{\mathrm{f}}\right)^{1 / 3}$ and $N=1 / L^{3}=3 V_{\mathrm{f}} / 4 \pi r_{\mathrm{G}}^{3}$, it can be clearly seen in Figure 7 that $L$ and $N$ remain almost constant at $373 \mathrm{~K}$ $\left(100{ }^{\circ} \mathrm{C}\right)$ for $\sim 36 \mathrm{ks}$, whereas a monotonous increase in $r$ and $L$ (and thus monotonous decrease in $N$ ) was observed at $463 \mathrm{~K}\left(190{ }^{\circ} \mathrm{C}\right)$. Similar trends will be extracted from SAXS spectra measured by Gomiero et al., ${ }^{[2]}$ in which almost identical values of $q_{\mathrm{m}}$ can be estimated for their 2091 alloy aged at RT for $450 \mathrm{ks}$, whereas a monotonous decrease in $q_{\mathrm{m}}$ is observable when aged at $423 \mathrm{~K}\left(150{ }^{\circ} \mathrm{C}\right)$ (see Figures $6(\mathrm{a})$ and 11(b) $\mathrm{in}^{[24]}$. The latter trend is typical of the nucleation and growth mechanism, but the former trend could be considered as indirect evidence of spinodal decomposition following after congruent ordering, although both mechanisms eventually result in the same precipitate microstructures of refined $\delta^{\prime}$ particles in the disordered matrix. In spinodally decomposed microstructures, $L$ can be regarded as a dominant composition modulation wavelength and, in the case of Al-Li alloys, equally as an average size of ordered domains formed by congruent ordering. In fact, such a depressed change in domain size is reported for an Al-7.9 at. pct Li binary alloy aged at $373 \mathrm{~K}\left(100^{\circ} \mathrm{C}\right)^{[25]}$ and the possibility of the occurrence of spinodal decomposition had been already pointed out by Spooner et al. ${ }^{[26]}$ for an Al-9.4 at. pet Li binary alloy aged at $373 \mathrm{~K}\left(100^{\circ} \mathrm{C}\right)$. Remember that spinodal decomposition (following after congruent ordering) proceeds independent of the existence of a number of grain boundaries in the HPT specimen because of a much smaller composition modulation wavelength, e.g., $\sim 9 \mathrm{~nm}$ (see Figure 7(b)), than the mean grain size, e.g., $\sim 206 \mathrm{~nm}$ (see Figure 4(f) or Table I).

\section{DISCUSSION}

\section{A. Difference in Age-Hardenability under SPD Condition}

In general, most of the metastable strengthening phases in age-hardenable aluminum alloys are formed by the nucleation and growth mechanism, and therefore if the alloys are cold-rolled or severely deformed before aging, heterogeneous nucleation at dislocations and grain boundaries becomes predominant in the subsequent aging stage. Such competitive precipitation produces sparsely distributed and coarsened precipitates, in place of refined transgranular precipitates, and thus plays no noteworthy role in strengthening of the alloys. The investigated HPT specimen of 6061 Al-Mg-Si aged at higher temperatures and 2091Al-Li-Cu aged at $463 \mathrm{~K}$ $\left(190{ }^{\circ} \mathrm{C}\right)$ was a case of showing the difficulty of concurrent strengthening by ultrafine-grained and precipitation hardenings. However, aging treatment at lower temperatures increased the hardness of the HPT specimen in the two different ways, e.g., $\Delta \mathrm{HV} 10$ at $343 \mathrm{~K}\left(70^{\circ} \mathrm{C}\right)$ for $6022 \mathrm{Al}-\mathrm{Mg}$-Si due to the slightly increased volume fraction of transgranular precipitates $^{[9]}$ and $>\Delta \mathrm{HV} 40$ at $373 \mathrm{~K}\left(100{ }^{\circ} \mathrm{C}\right)$ for $2091 \mathrm{Al}-\mathrm{Li}-$ $\mathrm{Cu}$ due to the refined precipitation of nanometer-scale particles regardless of ultrafine grains (Figure 4(f)). This significant difference in age-hardenability is well 
represented in Figure 8, where equivalent strain dependence of attained hardness and increment/decrement in hardness during aging is illustrated for a number of aluminum alloys in Table I. It is undoubtedly recognized that the HPT specimen of 2091Al-Li-Cu aged at $373 \mathrm{~K}\left(100^{\circ} \mathrm{C}\right)$ (as arrowed) possesses not only a remarkable level of attained hardness, i.e., >HV290 (Figure 8(a)), but also the good age-hardenability, i.e., $>\Delta$ HV40 (Figure 8(b)), even at quite large equivalent strain of $>100$. Remember that this uniqueness was the basis of the authors' classification of 2091Al- $\mathrm{Li}-\mathrm{Cu}$ into the alloy with a noteworthy effect of concurrent strengthening, but the others into the alloys with a limited effect.

\section{B. Alloy Designing for the Alloys that Decompose via the Nucleation and Growth}

As mentioned previously, concurrent strengthening by ultrafine-grained and precipitation hardenings has been hardly activated in most of the age-hardenable aluminum alloys. The results of 6022Al-Mg-Si in Section III-A are a typical example of the alloys that decompose via the nucleation and growth, i.e., reduced age hardenings and significant age softening, either of which occurs depending on the aging temperature applied (Figure 1). The problem is that the excellent age-hardenability of this alloy system is diminished to a great extent, resulting in the lower degree of concurrent strengthening, $K$. Here, $K$ is defined as a relative ratio of age-hardenabilities between the undeformed and coldrolled/HPT specimens at a given aging temperature.
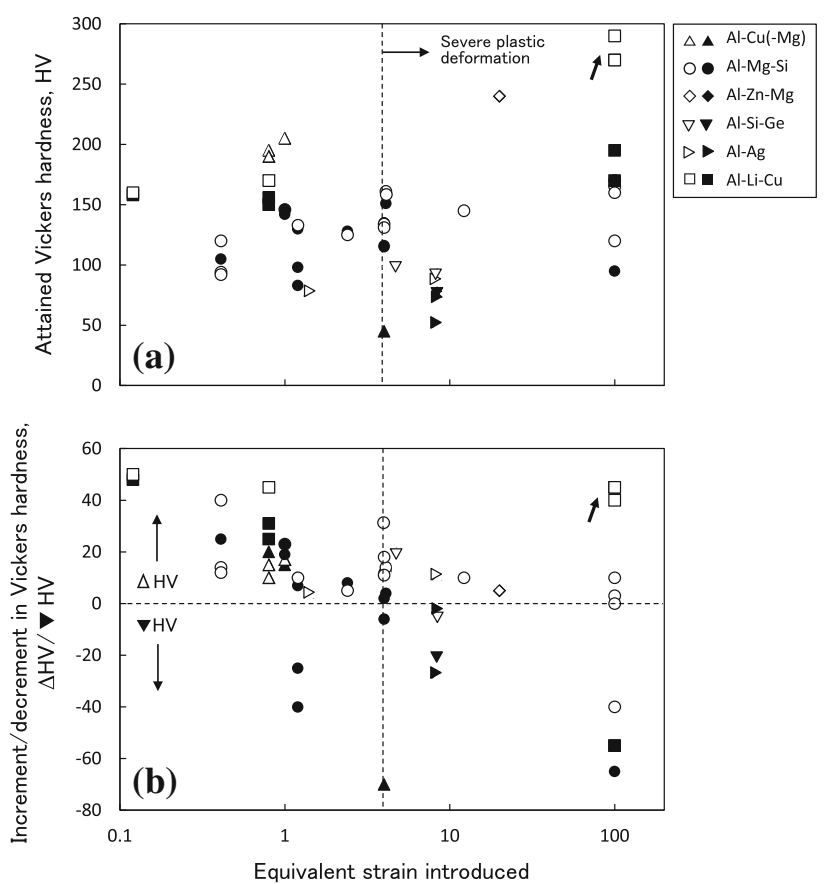

Fig. 8-Equivalent strain dependence of (a) attained Vickers hardness and $(b)$ increment/decrement in Vickers hardness during aging of various aluminum alloys in Table I. Open and solid symbols indicate the results at aging temperatures lower than or equal to $373 \mathrm{~K}$ $\left(100{ }^{\circ} \mathrm{C}\right)$, and higher than $373 \mathrm{~K}\left(100^{\circ} \mathrm{C}\right)$, respectively.
Under this definition, $K=1$ means that the addition law of strengthening mechanisms is validated. For the cold-rolled specimen with only equivalent strain of 0.41 (i.e., no SPD condition) for example, relatively high values of $K=0.3(\approx>\Delta H V 12 />\Delta H V 40)$ and $0.53(=\Delta \mathrm{HV} 40 / \Delta \mathrm{HV} 75)$ were estimated at $343 \mathrm{~K}$ and $443 \mathrm{~K}\left(70{ }^{\circ} \mathrm{C}\right.$ and $\left.170^{\circ} \mathrm{C}\right)$, respectively. On the other hand, lower values of $K=<0.25(=\Delta \mathrm{HV} 10 />\Delta \mathrm{HV} 40)$ and $-0.87(=\nabla \mathrm{HV} 65 / \Delta \mathrm{HV} 75)$ for the HPT specimen do represent the limited effect of concurrent strengthening by ultrafine-grained and precipitation hardenings in this temperature range. Most of the severely deformed and then artificially aged aluminum alloys in Table I (except 2091 Al-Li-Cu) are expected to possess such lower values of $K$, although lower aging temperatures disallow the precise determination of $K$ to be made due to their quite sluggish and unfinished increase in hardness/strength within the investigated aging time (For example, $K=<0.25$ was estimated from undetermined agehardenability of $>\Delta \mathrm{HV} 40$ ).

To maximize such limited effect of concurrent strengthening, the authors ${ }^{[10,11]}$ modeled competitive precipitation behavior among dislocations, grain boundaries, and the matrix based on a classical heterogeneous nucleation theory. The developed numerical model predicted the dislocation density and grain size dependence of simultaneous precipitation at different nucleation sites in good qualitative agreement with observed TEM microstructures in the undeformed, cold-rolled, and HPT specimens of 6022Al-Mg-Si (e.g., Figure 2). The model successfully showed that the larger the dislocation density or the smaller the grain size, the smaller the volume fraction of transgranular precipitates as is emphasized in previously mentioned feature (ii). Therefore, a method for designing can be drawn for the alloys that decompose via the nucleation and growth; i.e., the largest dislocation density and the smallest grain size should be preliminarily given without diminishing the amount of transgranular precipitates, for example, by half of the total precipitates. ${ }^{[10,11]}$ Lowering of aging temperature is another method to increase the volume fraction of transgranular precipitates, but the effect will be limited as suggested by the fact that the increment of hardness during aging is only as high as $\Delta \mathrm{HV} 30$ for a number of severely deformed age-hardenable aluminum alloys in Table I (except 2091Al-Li-Cu). Remember that the too severe plastic deformation plays a detrimental role in concurrent strengthening of the alloys that decompose via the nucleation and growth.

\section{Alloy Designing for the Alloys that Decompose via Spinodal Decomposition}

One of the most significant achievements in this study was to fabricate novel aluminum alloys with almost the highest level of hardness among conventional wrought aluminum alloys by means of concurrent strengthening by ultrafine-grained and precipitation hardenings. The results of $2091 \mathrm{Al}-\mathrm{Li}-\mathrm{Cu}$ in Section III-B verified that aging treatment at a lower temperature of $373 \mathrm{~K}$ $\left(100^{\circ} \mathrm{C}\right)$ increases the hardness of the HPT specimen up to $>$ HV290 because of the refined precipitation of the 
$\delta^{\prime}$ phase within ultrafine grains (Figures 3(a) and 4(f)). The corresponding degree of concurrent strengthening amounts to $K=0.53(=>\Delta \mathrm{HV} 40 />\Delta \mathrm{HV} 75)$, suggesting that high strength aluminum alloys can be fabricated if the combined processing of SPD and age-hardenings technique is applied to 2091 Al-Li-Cu. However, a higher aging temperature of $463 \mathrm{~K}\left(190^{\circ} \mathrm{C}\right)$ only induced significant age softening with a value of $K=-0.85(=\nabla$ HV55/DHV65. Figure 3(b)) and, therefore, the optimization of aging temperature also becomes important even for 2091Al-Li-Cu with noteworthy effect of concurrent strengthening.

From the obtained SAXS results for 2091Al-Li-Cu aged at $373 \mathrm{~K}\left(100{ }^{\circ} \mathrm{C}\right)$ (Figures 6(a) and 7), methods for designing can be drawn for the alloys that decompose via spinodal decomposition (following after congruent ordering); i.e., aging treatment should be performed at temperatures below spinodal boundaries to maximize the effect of concurrent strengthening by ultrafine-grained and precipitation hardenings. If the conventional aging temperatures cannot be changed, higher solute-concentrated alloys should be utilized, even if those alloy compositions are far from the ones currently in use for wrought aluminum alloys because SPD, especially HPT, could achieve the supersaturated solid solutions of excess amount of alloying elements. ${ }^{[27]}$ These criteria appear to be applicable to any alloy systems, and in fact the authors ${ }^{[28]}$ recently found that the HPT specimen of Al13.4 mass pct $\mathrm{Mg}$ alloy with equivalent strain of $>100$ possesses not only a remarkable level of attained hardness, i.e., HV296, but also the good age-hardenability, i.e., $\Delta$ HV31, after aging at $343 \mathrm{~K}\left(70^{\circ} \mathrm{C}\right)$ for $2226 \mathrm{ks}$. The age-hardenability was almost comparable to that in the undeformed specimen, i.e., $\Delta \mathrm{HV} 34$, leading to a quite high value of $K=0.91(=\Delta H V 31 / \Delta H V 34)$ and was certainly attributed to modulated structures corresponding to spinodal decomposition. Further investigation is in progress, especially to clarify the effects of (congruent) ordering during spinodal decomposition on concurrent strengthening of severely deformed age-hardenable aluminum alloys.

\section{CONCLUSIONS}

In this study, comprehensive and comparative studies on the age-hardenings behavior and precipitate microstructures of severely deformed and then artificially aged 6022Al-Mg-Si and 2091Al-Li-Cu alloys had been conducted to clarify whether or not concurrent strengthening by ultrafine-grained and precipitation hardenings is activated in a given alloy system and aging temperature. The obtained experimental results and our proposed methods for alloy designing are summarized below.

(i) The cold-rolled and high-pressure torsion (HPT) specimens of 6022Al-Mg-Si exhibited reduced age hardenings or significant age softening, depending on the aging temperature applied, failing to take advantage of the excellent age-hardenability of the undeformed specimen. This was because heterogeneous nucleation of coarsened precipitates becomes predominant at dislocations and grain boundaries in place of transgranular precipitates of the strengthening $\beta$ " phase (i.e., competitive precipitation). For the alloys that decompose via the nucleation and growth, therefore, the fabrication of optimal microstructures without diminishing the amount of subsequent transgranular precipitation becomes important as well as lowering of aging temperatures.

(ii) In contrast, the combined processing of severe plastic deformation (SPD) and aging treatment successfully activated concurrent strengthening of 2091Al-Li-Cu by ultrafine-grained and precipitation hardenings. Not just was the hardness of the HPT specimen (i.e., $>\mathrm{HV} 290$ at $373 \mathrm{~K}\left(100{ }^{\circ} \mathrm{C}\right)$ ) attained, but the higher degree of age hardenings (i.e., $>\Delta \mathrm{HV} 40$ ) was also achieved by refined precipitation of the $\delta^{\prime}-\mathrm{Al}_{3} \mathrm{Li}$ phase within ultrafine grains. From the obtained small-angle X-ray scattering (SAXS) results, methods for designing can be drawn for the alloys that decompose via spinodal decomposition; i.e., aging treatment should be performed at temperatures below spinodal boundaries, and if the conventional aging temperatures cannot be changed, higher solute-concentrated alloys should be utilized to maximize the effect of concurrent strengthening by ultrafine-grained and precipitation hardenings.

\section{ACKNOWLEDGMENTS}

This research was supported by the JST (Japan Science and Technology Agency) under collaborative research based on industrial demand "Heterogeneous structure control: Towards innovative development of metallic structural materials." S.H. thanks Prof. H. Okuda, Kyoto University, for helpful discussions on the SAXS measurement. The generous support by the Light Metals Educational Foundation of Japan and Japan Aluminum Association is also acknowledged.

\section{REFERENCES}

1. A. Azushima, R. Kopp, A. Korhonen, D.Y. Yang, F. Micari, G.D. Lahoti, P. Groche, J. Yanagimoto, N. Tsuji, A. Rosochowski, and A. Yanagida: Manuf. Technol., 2008, vol. 57, pp. 716-35.

2. S. Takaki: Bull. Iron Steel Inst. Jpn., 2008, vol. 13, pp. 44-49.

3. N. Tsuji, T. Iwata, M. Sato, S. Fujimoto, and Y. Minamino: Sci. Technol. Adv. Mater., 2004, vol. 5, pp. 173-80.

4. W.J. Kim, C.S. Chung, D.S. Ma, S.I. Hong, and H.K. Kim: Scripta Mater., 2003, vol. 49, pp. 333-38.

5. S. Cheng, Y.H. Zhao, Y.T. Zhu, and E. Ma: Acta Mater., 2007, vol. 55, pp. 5822-32.

6. W.J. Kim, J.K. Kim, T.Y. Park, S.I. Hong, D.I. Kim, Y.S. Kim, and J.D. Lee: Metall. Mater. Trans. A, 2002, vol. 33A, pp. 315564.

7. M.S. Tsai, P.L. Sun, P.W. Kao, and C.P. Chang: Mater. Trans. JIM, 2009, vol. 50, pp. 771-75.

8. M.R. Rezaei, M.R. Toroghinejad, and F. Ashrafizadeh: J. Mater. Process. Technol., 2011, vol. 211, pp. 1184-90.

9. S. Hirosawa: Yokohama National University, Yokohama, Japan, Unpublished Research, 2013. 
10. T. Masuda, S. Hirosawa, Z. Horita, and K. Matsuda: J. Jpn. Inst. Met., 2011, vol. 75, pp. 283-90.

11. T. Masuda, S. Hirosawa, Z. Horita, and K. Matsuda: Mater. Sci. Forum, 2012, vols. 706-709, pp. 1787-92.

12. M. Vaseghi and H.S. Kim: Mater. Des., 2012, vol. 36, pp. 735-40.

13. Z. Horita: Mater. Sci. Forum, 2006, vols. 519-521, pp. 1485-92.

14. K. Nakagawa, N. Tsuji, D. Terada, T. Nakano, K. Nizam, and T. Kanadani: J. Jpn. Inst. Light Met., 2012, vol. 62, pp. 442-47.

15. Y.H. Zhao, X.Z. Liao, S. Cheng, E. Ma, and Y.T. Zhu: $A d v$. Mater., 2006, vol. 18, pp. 2280-83.

16. Z. Horita: J. Jpn. Inst. Light Met., 2010, vol. 60, pp. 134-41.

17. Z. Horita, K. Ohashi, T. Fujita, K. Kaneko, and T.G. Langdon: Adv. Mater., 2005, vol. 17, pp. 1599-1602.

18. K. Ohashi, T. Fujita, K. Kaneko, Z. Horita, and T.G. Langdon: Mater. Sci. Eng., A, 2006, vol. 437, pp. 240-47.

19. S. Lee, Z. Horita, S. Hirosawa, and K. Matsuda: Mater. Sci. Eng., $A, 2012$, vol. 546, pp. 82-89.
20. H. Motoshima, S. Hirosawa, S. Lee, Z. Horita, K. Matsuda and D. Terada: Proc. 13th Int. Conf. Aluminum Alloys, 2012, pp. 939-44.

21. G. Sakai, Z. Horita, and T.G. Langdon: Mater. Sci. Eng., A, 2005, vol. 393, pp. 344-51.

22. Y. Ito and Z. Horita: Mater. Sci. Eng., A, 2009, vol. 503, pp. 32-36.

23. A.G. Khachaturyan, T.F. Lindsey and J.W. Morris Jr.: Metall. Trans. A, 1988, vol. 19A, pp. 249-58.

24. P. Gomiero, F. Livet, Y. Brechet, and F. Louchet: Acta Metal. Mater., 1992, vol. 40, pp. 847-55.

25. T. Sato and A. Kanio: Mater. Trans., JIM, 1990, vol. 31, pp. 25-30.

26. S. Spooner, D.B. Williams, and C.M. Sung: Aluminum-Lithium Alloys III, Inst. Metals, London, 1986, pp. 329-36.

27. K. Kaneko, T. Hata, T. Tokunaga and Z. Horita, Mater. Trans. JIM, 2009, vol. 50, pp. 76-81.

28. W. Goto, T. Hamaoka, S. Hirosawa, Z. Horita, S. Lee, K. Matsuda and D. Terada: Proc. 124th Conf. Japan Inst. Light Metals, 2013, in press. 